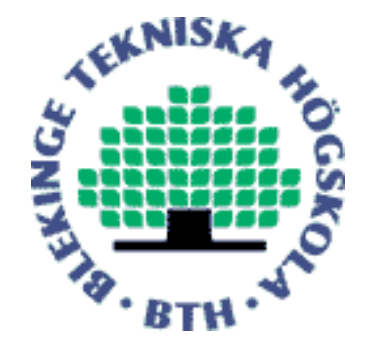

Copyright (C) 2012 IEEE.

Citation for the published paper:

Remotely Controlled Laboratory Setup for Active Noise Control and Acoustic Experiments

Imran khan, Dineshkumar Muthusamy, Waqas Ahmad, Ingvar Gustavsson, Johan

Zackrisson, Kristian Nilsson, Lars Håkansson

Remote Engineering \& Virtual Instrumentation (REV2012)

2012 Bilbao

This material is posted here with permission of the IEEE. Such permission of the IEEE does not in any way imply IEEE endorsement of any of BTH's products or services Internal or personal use of this material is permitted. However, permission to reprint/republish this material for advertising or promotional purposes or for creating new collective works for resale or redistribution must be obtained from the IEEE by sending a blank email message to pubs-permissions@iee.org.

By choosing to view this document, you agree to all provisions of the copyright laws protecting it. 


\title{
Remotely Controlled Laboratory Setup for Active Noise Control and Acoustic Experiments
}

\author{
I. Khan ${ }^{1}$, D. Muthusamy ${ }^{1}$, W. Ahmad ${ }^{1}$, K. Nilsson ${ }^{1}$, J. Zackrisson ${ }^{1}$, I. Gustavsson ${ }^{1}$, and L. Håkansson ${ }^{1}$ \\ ${ }^{1}$ Blekinge Institute of Technology, Department of Electrical Engineering, Karlskrona, Sweden.
}

\begin{abstract}
This paper presents a remotely controlled educational experiments setup for Active Noise Control (ANC) and acoustic experiments. The experiments setup is based on the Virtual Instruments Systems in Reality (VISIR) open source platform, National Instruments LabVIEW software and a Digital Signal Processor TMS320C6713 from Texas Instruments. The software development and equipment are controlled remotely form a client PC using a standard web browser. The proposed laboratory setup focuses on ANC experiments applied to noise in a ventilation duct. The laboratory setup will enable students to test and investigate properties and behaviour of adaptive algorithms in reality as compared to more confined simulations usually carried out in Matlab etc. The general steps in ANC, such as the feasibility of active control, designing, testing and debugging ANC algorithms, configuration and implementation of an active control system, are all covered. In addition students will be able to study the effect of analog to digital converters (ADC), anti-aliasing filters, digital to analog converters (DAC) and reconstruction filters using digital signal processing in reality, etc. The laboratory setup is suitable for a wide range of courses such as sound related experiments in upper secondary school physics, digital signal processing, adaptive signal processing, and acoustics at university level.
\end{abstract}

Index Terms-Active Noise Control, Remote Laboratories, VISIR.

\section{INTRODUCTION}

Educational laboratory experiments are essential in successful education both for engineering and non engineering studies. The overwhelming progress in communication technologies particularly the Internet, web services and the possibility of measurement instruments to be remotely accessed has enabled educational institutions to introduce innovative teaching techniques during the past two decades. With the introduction of open source course ware and numerous learning management systems, class room teaching is no more confined to the boundaries of a class room. These technological developments were adopted for Instructional (educational) laboratories prior to the class room teaching. The use of electronic measurement systems such as HP-35 an electronic slide rule with solid state memory can be found in 1972 while the use of computers for data collection and analysis can be seen since mid 1980s [1]. Today almost all of the laboratory setups are equipped with simulation, modelling tools and computer controlled data acquisition/analysis/measurement systems.

\section{A. Significance of Laboratory Education}

Engineering is a practical profession where knowledge is achieved by doing. In the early days of engineering education, the complete engineering education was delivered in laboratories [1] and even today most of the courses in engineering education comprise of laboratory education as well as classroom teaching. Accreditation boards such as European Network for Accreditation of Engineering Education (ENAEE) and Accreditation Board for Engineering and Technology (ABET) in America require adequate laboratory practice and resources for engineers [1][2][3]. Apart from the requirements of the accreditation boards current trends on the labour market have also increased the significance of a high quality laboratory education. Sophisticated technologies in industries require highly skilled manpower. Laboratory experiments may provide the necessary skills and training required for a professional career. The demand for skilled professionals is on the rise and many governments e.g. the Irish government plans to train 170,000 professionals to 3rd level by 2020 [4]. This means that educational institutions have to increase the resources for laboratory education substantially.

\section{B. Emergence of Remotely Controlled Laboratories}

The term remote or distance education is not a new concept in education. Most of the distance education programmes or courses have been replaced by online education or courses with the emergence of internet and web tools. The introduction of computer controlled data acquisition, measurement and analysis system and the possibility of their remote control have led to the development of remote, web or distance laboratories. The main purpose of these laboratories was to increase the usage of laboratory equipment in a more flexible and efficient way.

\section{Importance and Benefits of Remote Laboratories}

The requirement for skilled professionals and accreditation boards criteria have increased the need for hands-on experiments using real instruments and systems [4] while on the other hand the budget for education has declined in the recent years. Economic managers in institutions find laboratory education to be an easy victim. Laboratory equipments are expensive therefore both maintenance and up gradation of the equipment is affected and the overall result is reduced number of laboratory experiments per course. Recently humans have realized the need for sustainable development and efficient use of natural resources. Economic and political unification among different countries is encouraging mutual collaboration among educational institutions [5]. These are some of key factors which have stimulated universities to develop remote 
laboratories as compared to traditional laboratories [6][7][8]. Remote laboratories provide many advantages as compared to the traditional laboratories. The detailed discussion of these benefits can be found in [6][5][9]. With remote laboratories laboratory equipment can be managed in a very efficient manner by providing access around the clock with reduced maintenance, installation, and supervision costs. Institutions deprived of certain laboratory equipment can utilize remote laboratory facilities of other institutions and thus strengthen mutual collaboration. Above all the student will have the opportunity to get an extended access to laboratory equipment and work in more flexible and safer way from his/her own location.

\section{Challenges in Using Remote Laboratories}

According to the objectives set forth by ABET, students should work on physical equipments and systems to acquire the necessary skills such as analysis, creativity, teamwork, learning from failure and communication skills required for an engineering profession [1]. These objectives create one of the greatest challenge in the development of remote laboratories i.e. the students should have the same feeling of using real equipment and systems as in traditional hands-on laboratories [7]. This sense of genuineness can be improved with the help of some kind of audio or visual feedback to enhance the student's interaction with the laboratory equipment [10][11]. The second issue usually discussed, is that remote laboratories are compared with simulation and hands-on laboratories with real instruments in terms of their effectiveness. This comparison is inconclusive as each laboratory has its own merits, scope and limitations. Simulations and modelling tools require huge computing resources and are limited to simplified models ignoring real world complexities e.g. non-linearity non-stationarity and noise. Traditional laboratories with real equipment are expensive and are available to students for limited time. These issues are more thoroughly discussed in [4][9][12][13]. Another main challenge for remote laboratories is the lack of standards, protocols, compatibility and common software tools which resulted in numerous different efforts based on different architectures [6][8][14][15]. This challenge can be tackled by industrial cooperation to develop standard communication protocols such as the Interchangeable Virtual Instruments (IVI) and Virtual Instrument Software Architecture (VISA) for laboratory equipment. More collaboration among universities e.g. the Virtual Instruments Systems In Reality (VISIR) project initiated by Blekinge Institute of Technology (BTH) Sweden, can promote the use of common architecture and software tools [5][16][17][18].

\section{E. Current State of the Art}

The notion of remote laboratories had started with the Internet in 1970s and till now numerous universities across the globe have developed remote laboratories for different courses based on different architectures and software tools [6][16][19]. BTH initiated its research on remote laboratories in 1999 which materialized in the form of the VISIR project in 2006 [18]. The aim of the VISIR project was to develop distributed laboratories working as nodes of a grid on common open source software and hardware platforms. The idea was soon adopted by other universities across Europe and Asia [5][20][21]. So far BTH has developed three remotely accessible instructional laboratories for electronic circuits, vibration analysis and antenna theory courses [8].

\section{F. Motivation for Active Noise Control Laboratory}

The field of Active Control (AC) for sound and vibration had received considerable attention at the department of Electrical Engineering at BTH mainly due to a strong faculty in the area [22][23]. Several courses related to the field such as sound and vibration analysis, experimental mechanics and adaptive signal processing are regularly given at the department. These courses demand significant hands-on experience of both equipment and physical systems to acquire adequate knowledge and future employment benefits [24][25]. The experimental work in such courses are carried out in time limited scheduled laboratory sessions supported by computer simulation and modelling in conventional laboratories. The equipments used in these laboratories such as signal analyzer, shakers and accelerometers/microphones are expensive and usually one setup is available per course. With the large number of students and other research activities such as $\mathrm{PhD}$ and Masters thesis these laboratory equipment prove to be insufficient. The department has already developed a remote laboratory for vibration analysis of mechanical structures complementing existing traditional laboratories [26]. Observing the benefits of the current remote laboratories at BTH and the deficiency of experimental equipment for ANC instigated the development of the proposed remotely controlled laboratory. This laboratory setup is primarily developed for ANC experiments but can be used for digital signal processing and acoustic courses as well using real hardware and systems rather than simulations.

\section{Description Of The Laboratory Setup}

The proposed prototype of the remote ANC laboratory can be divided in to three main parts i.e. hardware components, measurement and equipment server and remote development server as shown in Fig. 1 as a block diagram while the actual hardware components are shown in Fig. 2. Each of these parts are described briefly in the following sections.

\section{A. Hardware Components}

The experimental setup concerns a single channel feed forward active noise control (ANC) of noise in ventilation duct [13]. The laboratory setup consists of a circular ventilation duct that is $4 \mathrm{~m}$ long with an inner diameter of $315 \mathrm{~mm}$. In the duct four reference microphones and one error microphone (VM-6052-5382) are installed. At both ends of the ventilation duct a speaker is installed (Fostex 6301B3). A four channel dynamic signal analyzer (HP36570A) is connected to the measurement and equipment server via General Purpose Interface Bus (GPIB). The analyzer is used for analysis of control and measurement signals as well as signal source to one of the 


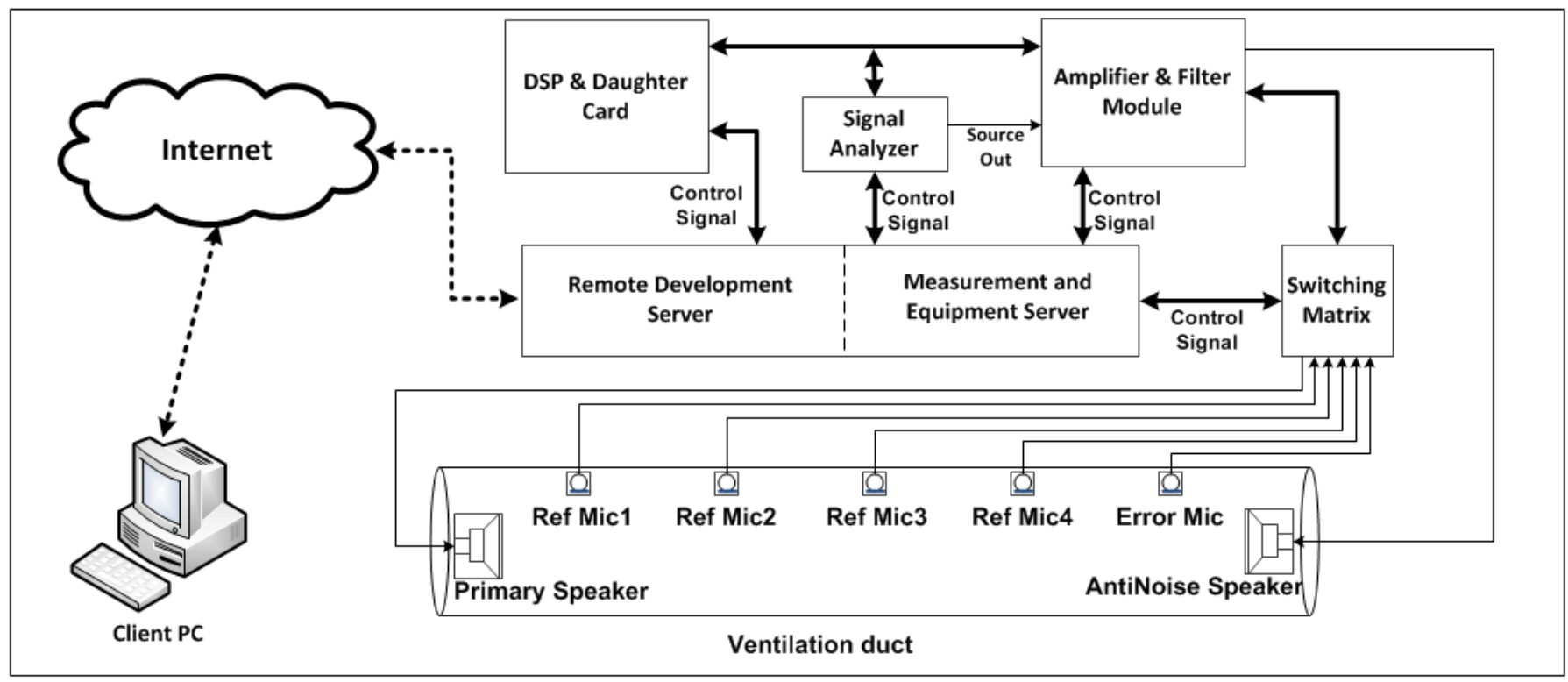

Figure. 1. Block diagram of the proposed remote ANC laboratory setup

speakers (primary noise speaker). The other speaker is used to generate the so called anti-noise in the experimental setup when carrying out active noise control. The laboratory setup has a signal processing module i.e. TMS320C6713 DSP from Texas Instruments connected to the server via USB (Universal Serial Bus). The signals to and from the DSP processor are conditioned by anti-aliasing filters/amplifiers USBPGF-S1/L from Alligator Technologies. The analog to digital and digital to analog conversion is achieved through a 16 bit daughter card module (S. Module 16-100) from SEMATIC, connected to the DSP board via mini-bus interface. One of the challenging tasks in performing ANC experiments from remote computer is the handling of different hardware setup or configurations that involve changing cables form microphones and speakers. A telemanipulator (or Switching Matrix) [27] that can switch cables between microphone and speaker based on command

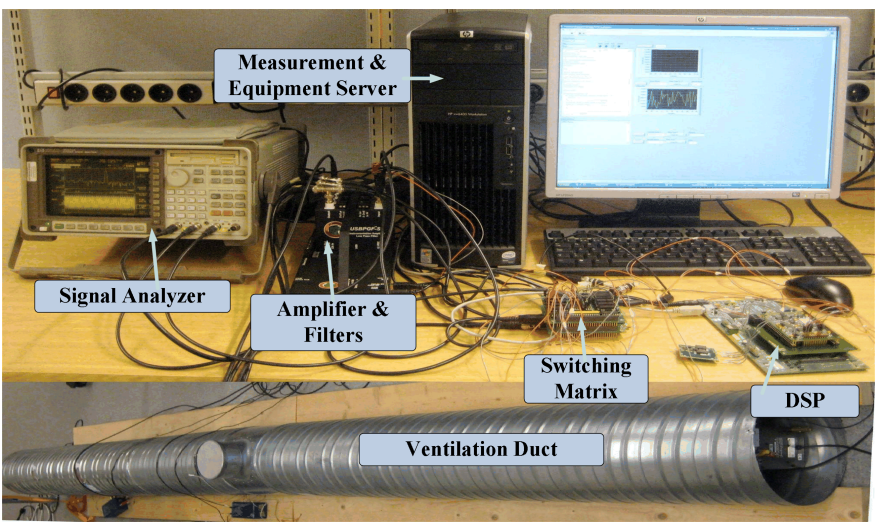

Figure. 2. A snap-shot of the proposed remote laboratory hardware setup form the measurement and equipment server is used. The working setup of the presented laboratory is shown in Fig. 2.

\section{B. Measurement and Equipment Server}

As shown in the block diagram of the laboratory in Fig. 1 the measurement and equipment server acts as a link between the experimental setup and the internet. The client-server architecture for the proposed remote ANC laboratory is inherited from open electronics laboratory in BTH [28].

\section{Remote Development Server}

One of the important steps involved in performing ANC experiments is to implement an adaptive algorithm using a DSP. To program the DSP remotely a remote development server that integrates the Code Composer Studio 3.1 (CCS) from Texas Instruments and LabVIEW from National Instruments is used. Using LabVIEW's built in web-publishing tool the remote development server is made accessible from a remote computer. Thereby programming and debugging the DSP from remote computer is made possible.

\section{Client Interface}

In the remote laboratories the client interface will be the interaction point for the students and the hardware and equipments placed in the laboratory. The presented laboratory has two such client interface one concerning the measurement and configuration of hardware and the other concerning the remote debugging of DSP. These two client interfaces are discussed in the following sections.

\section{A. Measurement and Configuration Client}

The measurement and configuration client shown in Fig. 3 has the schematic diagram of the experimental setup. The 


\section{Measurement and Configuration Client}

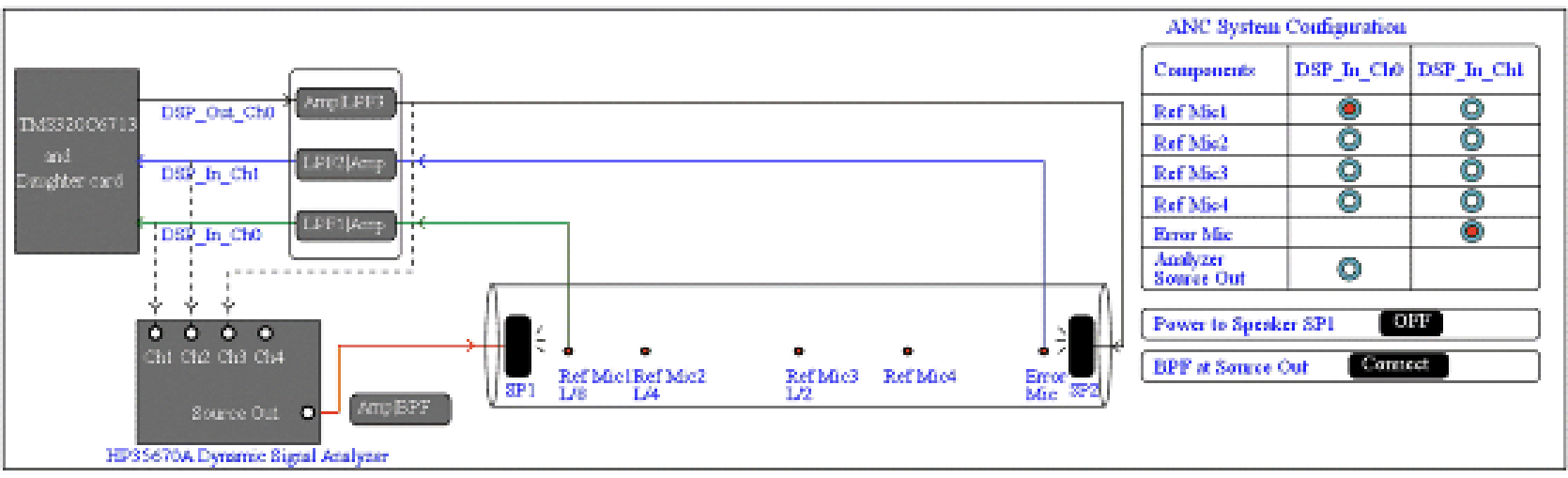

\section{Signal Conditioning Module}

Amplifier and LPF 1: Coipling $>>A C \&$ Gain $>>$

Amplifier and LPF 2: Cotpling $\gg A C \sim$ Gain $\gg 1$

- Corner Frequency (in $\mathbf{H z})>200$

Amplifier and LPF 3: Conpling $\gg A C *$ Gain $\gg 1$

Corner Frequency (in Hz) $>200$

Amplifier and BPF ; Coupling $>$ AC $\sim$ Gain $>1>0$ Comer Frequency (in Hz): LPF $>>200$

Measure

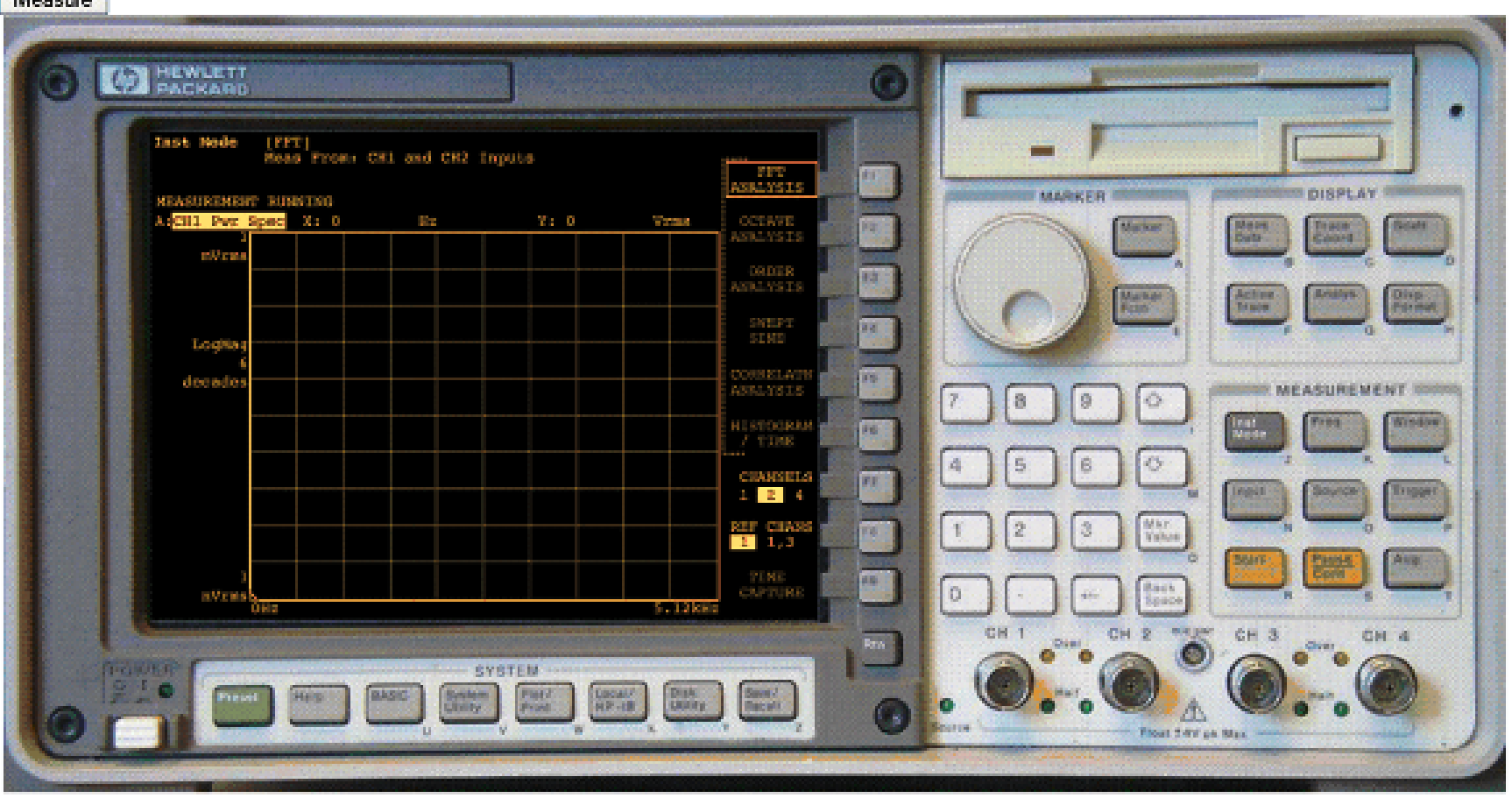

Remote Debug Environment: Launch

Figure. 3. Measurement and configuration client interface

configuration tab in the top right corner can be used to select one of the microphones installed in the duct. Selecting a microphone connects the microphone to the amplifier and filter module that corresponds to the input channel of the data acquisition card. Since the signal sensed by the microphone is week in amplitude and susceptible to high frequency noise, it has to be conditioned i.e. amplified and filtered by anti-aliasing filters. The signal conditioning part of the measurement and configuration client can be used to select various parameters required like $\mathrm{AC} / \mathrm{DC}$ coupling, amplifier gain and cut-off 
frequency for the anti-aliasing and re-construction filters. The FLASH front end of signal analyzer is shown in Fig. 3 can be used to control the signal analyzer in the experimental setup. This acts as source of signal generation and for analysis of the signal coming from amplifier and filter modules. Thus the measurement and configuration client can be used to perform various acoustic experiments.

\section{B. Remote Development Environment}

The remote development environment (RDE) shown in Fig. 4 provides basic functionalities of CCS IDE e.g. file and project creation, compiling the source code and downloading the executable to the DSP. The RDE supports plots during execution of the DSP and capability to read the variables used in the algorithm.

\section{OPERATION OF REMOTE LABORATORY}

The remote ANC laboratory presented in this paper has various capabilities such as configuring the hardware setup for experiments, measuring the signals from microphone, remote development of signal processing algorithm, etc. There are various experiments that are possible with this remote laboratory that are broadly classified as,

1) Acoustic experiments

2) Digital signal processing experiments

3) Active noise control experiments

How these experiments are performed is explained in the following sections,

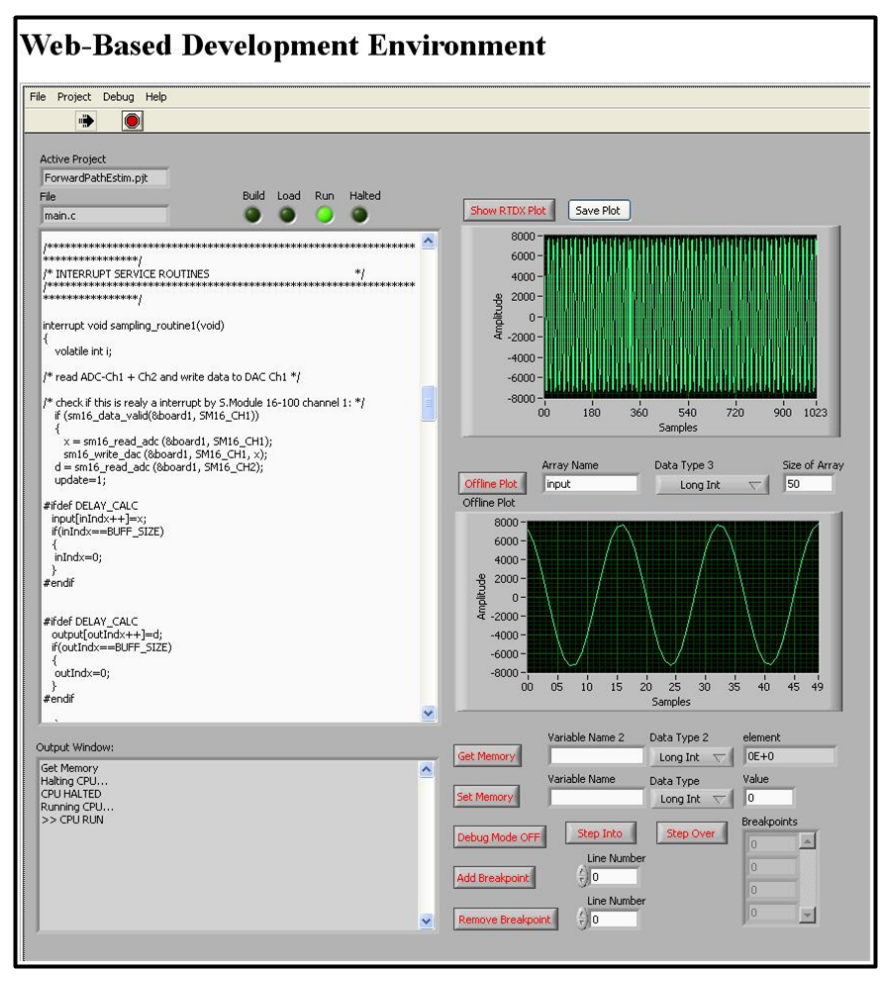

Figure. 4. Remote development environment

\section{A. Acoustic Experiments}

Various acoustic experiments concerning the acoustic properties of the duct can be performed with the experimental setup. Acoustic experiments can be classified as basic measurement experiments like measuring sound pressure,intensity, power spectral density (PSD) of noise and so on. The other category is the advanced experiments based on the acoustic properties of the duct such as measuring the mode shapes in the duct. Fig. 5 shows the acoustic modes and corresponding microphone positions in the duct.

\section{B. Digital Signal Processing Experiments}

The capability of the remote laboratory to program and debug the DSP from remote computer enables the students to experiment various signal processing algorithms and filter implementations. Using RDE and measurement and configuration client students can perform experiments such as,

- FIR and IIR Filter implementation.

- Adaptive signal processing algorithms (e.g. LMS, NLMS and so on)

- Real time programming using interrupts and timers.

- Device drivers for ADC and DAC used with daughter card.

\section{Active Noise Control Experiments}

In this section various ANC steps involved in performing ANC experiments are discussed in detail. Schematic diagram for single channel feed forward ANC system is shown in Fig. 6 . The signal $x(n)$ sensed by the reference microphone is fed to the adaptive filter as reference signal. Then the reference signal $x(n)$ is filtered through the estimated forward path $F^{\prime}$ to get the signal $X_{F^{\prime}}(n)$. The control signal $y(n)$ generated by the adaptive algorithm is fed to the anti noise speaker to cancel out the noise in the duct. The signal $e(n)$ sensed by the error microphone placed near the anti noise speaker is fed to the adaptive algorithm as error signal. The signal generated by the anti noise speaker is also sensed by the reference microphone which produces feedback effect.In order to minimize the feedback effect a feedback neutralization filter is implemented and its output signal $X_{B^{\prime}}(n)$ is subtracted from

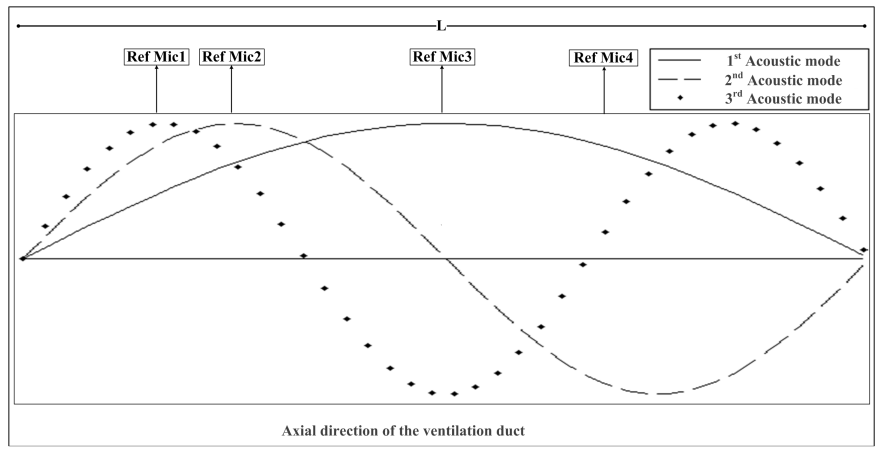

Figure. 5. Typical illustration of first, second and third acoustic modes in the ventilation duct along the axial direction of the duct 


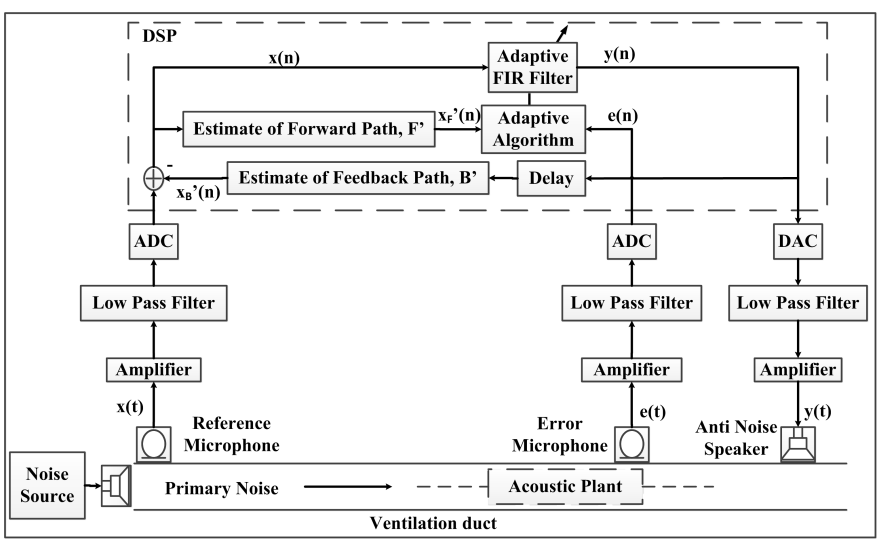

Figure. 6. Schematic diagram of ANC System

the reference signal $x(n)$. The feedback neutralization filter uses estimated feedback path $B^{\prime}$ to filter the control signal $y(n)$ to get the signal $X_{B^{\prime}}(n)$ [25]. In the next section the procedure to estimate the forward path and feedback path is discussed.

System Identification: Estimate of forward and feedback paths are important for the better performance of ANC. The control signal path from the Digital to Analog Converter (DAC), low pass filter, amplifier, anti-noise speaker, acoustic path, error microphone, low pass filter, amplifier and Analog to Digital Converter (ADC) form the forward path. While the control signal path from the Digital to Analog Converter (DAC), low pass filter, amplifier, anti-noise speaker, acoustic path, reference microphone, low pass filter, amplifier and Analog to Digital Converter (ADC) form the feedback path. In order to estimate these paths system identification technique shown in Fig. 7 is used. A random noise signal in the range [0$200 \mathrm{~Hz}]$ can be used as an identification signal $x(n)$ to excite the desired path. The output sensed by the desired microphone

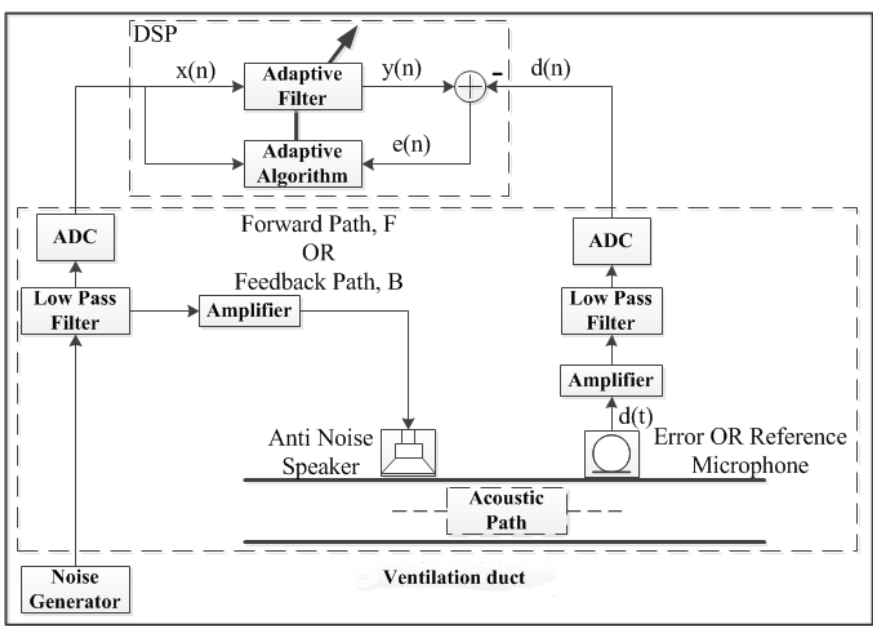

Figure. 7. Schematic diagram of system identification experiment

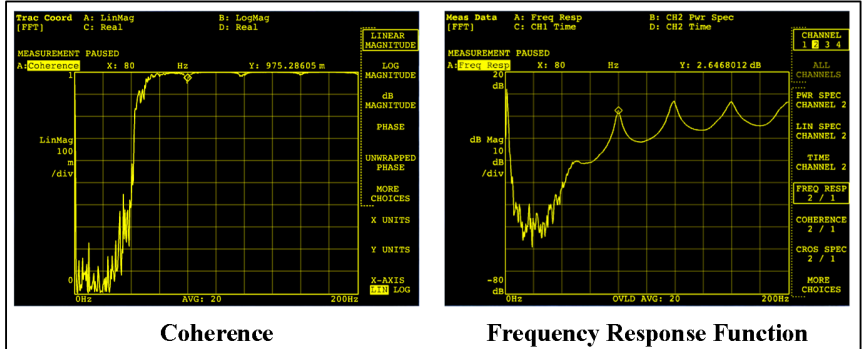

Figure. 8. Coherence and Frequency Response Function of transfer path between reference and error microphones

(error or reference) will be the desired signal $d(n)$. Both the signals $x(n)$ and $d(n)$ are fed to the DSP. System identification based on the LMS algorithm may be implemented in the DSP where error signal $e(n)$ is the difference of filtered output signal $y(n)$ and desired signal $d(n)$.

Frequency Domain Analysis: The transfer paths discussed in the system identification section namely forward path and feedback path are assumed to be linear. In reality these transfer paths may not be linear. The coherence function estimate between reference and error microphone signal and frequency response response functions may be used to study the properties of the transfer path. From the frequency response function the resonant frequency may be estimated and this information can be used to attenuate noise in the duct. Fig. 8 shows the typical coherence and frequency response function between reference and error microphone.

Performing ANC Experiment Using the Proposed Laboratory: The measurement and configuration client can be used to select the appropriate microphone to be connected to the DSP input channel as discussed in section IV-A. A typical ANC system configuration for forward path estimation is shown in Fig. 9. During the forward path estimation the primary speaker has to be muted and the anti-noise speaker has to be excited with identification signal. The random noise from the signal analyzer may to be fed to the input channel of DSP as identification signal. After the experimental setup is configured the system identification algorithm such as least mean square (LMS) can be implemented and tested using RDE. In a similar way appropriate reference microphone may be used to estimate the feedback path. Once the forward path and feedback path are estimated the system may be configured for ANC experiment as shown in Fig. 10. During ANC experiment a bandlimited random noise is fed to the primary speaker and the signal sensed by the reference microphone is fed to the signal conditioning module and then to the DSP as reference signal for ANC algorithm. The usage of bandpass filter is optional to limit the control bandwidth as required. RDE may be used for implementing ANC algorithm such as Filtered X-Least Mean Square (Fx-LMS)algorithm. The feedback path estimate may be used for feedback neutralization [25]. 


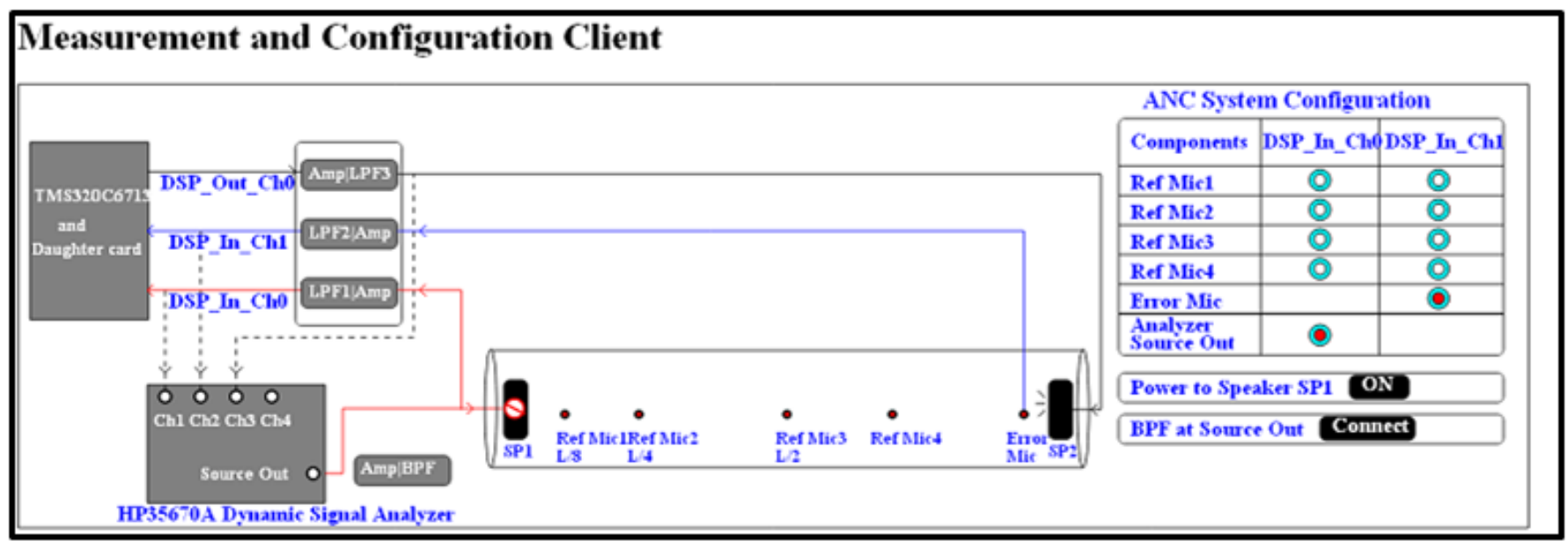

Figure. 9. A typical system configuration for forward path estimation using the measurement and configuration client

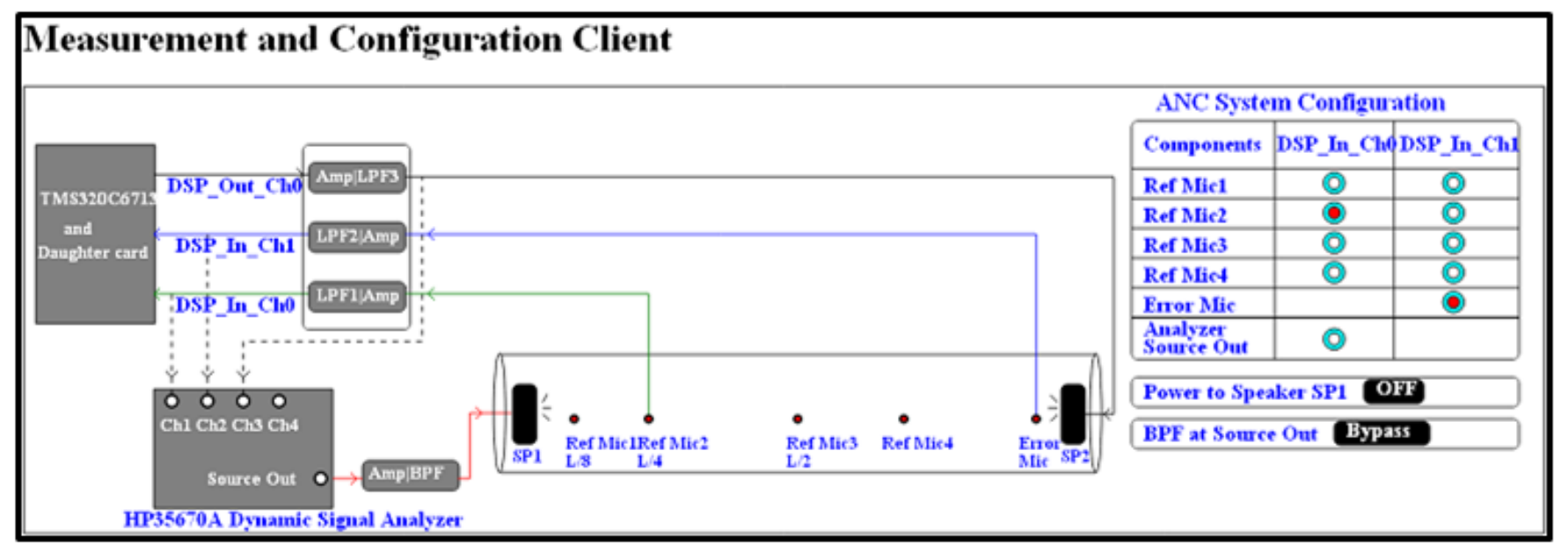

Figure. 10. A typical system configuration for ANC experiment using the measurement and configuration client

\section{SUMmARY AND CONCLUSION}

This paper presents a multi-purpose remotely controlled ANC Laboratory setup. The laboratory is remotely controlled, configured, programmed and debugged through user friendly graphical interfaces using a standard web browser. The features of the laboratory can be used to teach courses on e.g. Digital Signal Processing, Adaptive Signal Processing and Acoustics. The proposed laboratory can be extended to support a multi channel ANC system audio/visual feed back and administrative scheduling.

\section{REFERENCES}

[1] L.D. Feisel and A.J. Rosa, "The role of the laboratory in undergraduate engineering education," Journal of Engineering Education, vol. 94, pp. $121-130,2005$

[2] "European Network for Accreditation of Engineering Education (ENAEE)," http://www.enaee.eu/wp-content/uploads/2012/01/ EUR-ACE_Framework-Standards_2008-11-0511.pdf, June, 2012, [Online; accessed 10-June-2012].
[3] "Accreditation Board for Engineering and Technology (ABET)," http://www.abet.org/uploadedFiles/Accreditation/Accreditation_Process/ Accreditation_Documents/Current/tac-criteria-2012-2013.pdf, June, 2012, [Online; accessed 10-June-2012].

[4] M. McAfee and S. Reid, "Challenges in providing practical labs online to distance learning students," University College Cork, Ireland, 2010.

[5] A. Nafalski, Z. Nedic, J. Jan Machotka, . Gl, A. Scarino, J. Crichton, I. Gustavsson, J. M. Ferreira, D. Lowe, and S. Murray, "International collaboration in remote engineering laboratories: an approach to development," 2009.

[6] L. Gomes and S. Bogosyan, "Current trends in remote laboratories," Industrial Electronics, IEEE Transactions on, vol. 56, no. 12, pp. 4744 -4756, Dec. 2009.

[7] I. Gustavsson, J. Zackrisson, H. Akesson, L. Hakansson, I. Claesson, and T. Lago, "Remote operation and control of traditional laboratory equipment," International Journal of Online Engineering, vol. 2, no. 1, p. 8 pp., 2009.

[8] I. Gustavsson, K. Nilsson, J. Zackrisson, J. Garca Zubia, U. Hernndezjayo, A. Nafalski, Z. Nedic, Gl, J Machotka, M. I. Pettersson, T. Lag, and L. Hkansson, "On objectives of instructional laboratories, individual assessment, and use of collaborative remote laboratories," IEEE Transactions on Learning Technologies, vol. 2, no. 4, pp. 263-274, Dec. 2009. 
[9] J. Ma and J. V. Nickerson, "Hands-on, simulated, and remote laboratories: A comparative literature review," ACM computing surveys, vol. 38, no. 3 , p. 7, 2006

[10] D. Lang, C. Mengelkamp, R. S. Jger, D. Geoffroy, M. Billaud, and T. Zimmer, "Pedagogical evaluation of remote laboratories in eMerge project," European Journal of Engineering Education, vol. 32, no. 1, pp. 57-72, Mar. 2007.

[11] M. Casini, D. Prattichizzo, and A. Vicino, "The automatic control telelab: a user-friendly interface for distance learning," IEEE Transactions on Education, vol. 46, no. 2, pp. 252- 257, May 2003.

[12] R.V. Krivickas and J. Krivickas, "Laboratory instruction in engineering education," Global J. of Engng. Educ., Published in Australia, vol. Vol.11, No.2.

[13] J. E. Corter, J. V. Nickerson, S. K. Esche, C. Chassapis, S. Im, and J. Ma, "Constructing reality: A study of remote, hands-on, and simulated laboratories," ACM Trans. Comput.-Hum. Interact., vol. 14, no. 2, Aug. 2007. [Online]. Available: http://doi.acm.org/10.1145/1275511.1275513

[14] “MIT, Remote Labs,” http://icampus.mit.edu/ilabs/, June, 2012, [Online; accessed 12-June-2012].

[15] I. Gustavsson, J. Zackrisson, K. Nilsson, J. Garcia-Zubia, L. Hkansson, I. Claesson, and T. Lag, "A flexible instructional electronics laboratory with local and remote lab workbenches in a grid," Intl J. Online Eng, vol. 4, no. 2, 2008. [Online]. Available: http://www.bth.se/fou/forskinfo. nsf/all/5f3b8d528f37f080c125744400534c2d

[16] A. Baccigalupi, C. De Capua, and A. Liccardo, "Overview on development of remote teaching laboratories: from LabVIEW to web services," in Instrumentation and Measurement Technology Conference, 2006. IMTC 2006. Proceedings of the IEEE, Apr. 2006, pp. 992 -997.

[17] Y. Yan, Y. Liang, X. Du, H. Hassane, and A. Ghorbani, "Putting labs online with web services," IT Professional, vol. 8, no. 2, pp. $27-34$, Apr. 2006.

[18] I. Gustavsson, T. Lag, L. Hkansson, J. Zackrisson, and I. Claesson, "The VISIR project an open source software initiative for distributed online laboratories," in REV 2007, Jan. 2007.

[19] A. F. Almarshoud, "The advancement in using remote laboratories in electrical engineering education: a review," European Journal of Engineering Education, vol. 36, no. 5, pp. 425-433, 2011. [Online].
Available: http://www.tandfonline.com/doi/abs/10.1080/03043797.2011. 604125

[20] M. Tawfik, E. Sancristobal, S. Martin, C. Gil, A. Pesquera, P. Losada, G. Diaz, J. Peire, M. Castro, J. Garca Zubia, U. Hernndez, P. Ordua, I. Angulo, M.A. Marques, M.C. Viegas, and G.R. Alves, "VISIR: experiences and challenges," International journal of online engineering, vol. 8, no. 1, pp. 25-32, Feb. 2012.

[21] U. Hernandez-Jayo, J. Garca-Zubia, I. Angulo, D. Lopez-de-Ipia, P. Ordua, J. Irurzun, and O. Dziabenko, "LXI technologies for remote labs: An extension of the VISIR project," International Journal of Online Engineering (iJOE), vol. 6, no. 5, pp. pp. 25-35, Aug. 2010. [Online]. Available: http://www.online-journals.org/index.php/ i-joe/article/view/1385

[22] "Research by Department of Electrical Engineering, BTH," http://www.bth.se/fou/forskinfo.nsf/departments!OpenView\&Start= $1 \&$ Count=30\&Expand=14\#14, June, 2012, [Online; accessed 10-June2012].

[23] "Research by Department of Signal Processing, BTH," http://www.bth.se/fou/forskinfo.nsf/departments!OpenView\&Start= $1 \&$ Count $=30 \&$ Expand $=14 \# 14$, June, 2012, [Online; accessed 10-June2012].

[24] A. Brandt, Noise and Vibration Analysis: Signal Analysis and Experimental Procedures. John Wiley \& Sons, Apr. 2011.

[25] Sen M. Kuo and Dennis R. Morgan, Active noise control systems: algorithms and DSP implementations. Wiley, 1996.

[26] H. kesson, I. Gustavsson, L. Hkansson, and I. Claesson, "Remote experimental vibration analysis of mechanical structures over the internet," in ASEE Annaual Conference, Jan. 2005.

[27] I. Gustavsson, J. Zackrisson, J. S. Bartunek, K. Nilsson, L. H \aakansson, I. Claesson, and T. Lag, "Telemanipulator for remote wiring of electrical circuits," in Proceedings of the 2008 REV Conference, Dsseldorf, Germany, 2008.

[28] K. Nilsson, J. Zackrisson, and M. Pettersson, "Remote access of computer controlled experiments," International Journal of Online Engineering (iJOE), vol. 4, no. 4, pp. pp. 52-56, Oct. 2008. [Online]. Available: http://www.online-journals.org/index.php/ i-joe/article/view/704 